\title{
Assessment of serum zinc, calcium and magnesium among Sudanese patients with senile cataract in Khartoum State-Sudan.
}

\author{
Rehab OM Altouhami, Abdalla E Ali* \\ Department of Clinical Chemistry, Faculty of Medical laboratory Sciences, Alzaiem Alazhari University, Sudan
}

\begin{abstract}
Background: Senile cataract is a vision-impairing disease caused by age, and it is characterized by the gradual progressive thickening of the lens in the eye. The purpose of the study was to assess the serum level of Zinc, Magnesium and Calcium in senile cataract patients.
\end{abstract}

Material and Methods: Ninety four individuals classified into two groups, $\mathbf{5 0}$ as case group and 44 as healthy individuals as control group. Atomic absorption spectroscopy was used to measured serum Zinc, Calcium and magnesium.

Results: Means of serum Calcium, Magnesium and Zinc levels in patient with senile cataract were $7.82 \pm 1.98 \mathrm{mg} / \mathrm{dL}, 1.31 \pm 0.41 \mathrm{mg} / \mathrm{L}$ and $0.27 \pm 0.04 \mathrm{mg} / \mathrm{L}$ respectively, this study revealed that there were significant differences in serum Zinc levels, Magnesium levels, between case and control P-value (0.00 and 0.017$)$ respectively; But insignificant differences in serum Calcium levels P-value (0.16).

Conclusion: The study findings that decrease of serum zinc and magnesium levels were play a role in developmental mechanism of the senile cataract or cataract risk factors.

Keywords: Senile, Cataract, Zinc, Magnesium, Calcium.

Accepted on August 08, 2018

\section{Introduction}

Eye is the most amazing organ in human body and lens is one of the most notable structures within it. The main function of the lens is to reflect the light to focus it on the retina any pacification in crystalline lens is called cataract [1]. It is account for over half of the cases of blindness. Senile cataract is physiology disorder of the eye occurring in the elderly persons caused by a multifactorial disease and there are other factors, which contribute to the aging lens changes, characterized by an initial opacity in the lens subsequent swelling of the lens and final shrinkage with complete loss of transparency [2]. The lens possesses impressive array of protein that are coupled to release of the intracellular calcium they include membrane of the muscarinic, adrenergic, and purinergic families [3]. Calcium in the lensis related with the normal permeability and regulation of dynamic equilibrium between the ionic constituents of the lens and its surrounding fluid. It is said that an accumulation of Calcium in the intact lens induces formation of high molecular weight proteins, which may be associated with the loss of lens transparency [4], Caused by prolonged increase in intracellular calcium would be expected to activate proteases such as calpain so any interference within the lens is also likely to have a cataract. Hypocalcaemia causes cataractous changes may be associated with parathyroid tetany [5].

Development of cataract in senile age group is supposed to be due to multiple factors. Increased lipid peroxidation due to oxidative stress has been proved to be an important factor of those [6]. Oxidative stress generally causes damage to the membrane polyunsaturated fatty acids (PUFA) leading to generation of malondialdehyde (MDA), a thiobarbituricacidreacting substance
(TBARS). The superoxide dismutase (SOD), on the other hand, functions mainly as a first order antioxidant enzyme, mainly by neutralizing the effect of superoxide anion which is an important precursor for oxidative stress in the tissues $[7,8]$. Human SOD is mainly dependent on the metal zinc for its structural stability [9]. Also Zinc play a role in the maintaining normal ocular function it is presents in high concentration in ocular tissue [5]. Membrane transport mechanism sutilizing several magnesium (Mg)-dependent ATPases, play an important role in maintaining lens homeostasis. Therefore, in Mg-deficiency states, ATPase dysfunctions lead to intracellular accumulation of $\mathrm{Ca}\left(2^{+}\right)$. High intracellular $\mathrm{Ca}\left(2^{+}\right)$causes activation of the enzyme calpain II, which leads to the denaturation of crystalline, the soluble lens protein required for maintaining the transparency of the lens. Mg deficiency also interferes with ATPase functions by causing cellular ATP depletion. Furthermore, Mg deficiency enhances lenticular oxidative stress by increased production of free radicals and depletion of antioxidant defenses. Therefore, $\mathrm{Mg}$ supplementation may be of therapeutic value in preventing the onset and progression of cataracts in conditions associated with $\mathrm{Mg}$ deficiency [10].

\section{Material and Methods}

This Cross sectional study was conducted at Makkah Eyes hospital, among 94 individuals classified into two groups, 50 as case group and 44 as healthy individuals as control group. All data analyzed by using the statistical package for Social Sciences (SPSS); chi squire, independent t-test and parson correlation test. P-value less than 0.05. Cataracts patients aged above fourty included in the study. Any patients with systemic disease excluded from this study. After signing an informed 
Citation: Altouhami ROM, Ali AE. Assessment of serum zinc, calcium and magnesium among Sudanese patients with senile cataract in Khartoum State-Sudan. Ophthalmol Case Rep. 2018;2(2):1-3.

consent the medical history was taken from each participant (cases and controls) using questionnaire.

Three ml of venous blood was taken under septic condition from each group of the study, the sample allowed to clot, centrifuged at $(3000 \mathrm{rpm})$ for 5 minutes in plain tubes. Serum was stored at $-20^{\circ} \mathrm{C}$ until analysed in the medical laboratory for serum Zinc, Magnesium and Calcium. Zinc, Magnesium and Calcium measured by Atomic absorption spectroscopy occurs when a ground state atom absorbs energy in the form of light of a specific wavelength and is elevated to an excited state. The amount of light energy absorbed at this wavelength will increase as the number of atoms of the selected element in the light path increases. The relationship between the amount of light absorbed and the concentration of analyses present in known standards can be used to determine unknown sample concentrations by measuring the amount of light they absorption. The use of special light sources and careful selection of wavelength allow the specific quantitative determination of individual elements in the presence of others.

\section{Statistical Analysis}

The data was recorded and analyzed using statistical package for social sciences (SPSS version 20) on programmed computer. The mean standard deviations of variable were calculated for both the test group and the control group and P-value for comparison was obtained $\mathrm{P}$-value $\leq 0.05$ was considered significant. $\mathrm{T}$ test and correlation were used to access the relationship between different variable.

\section{Result}

The present study was conducted using total of ninety for participants. Means of serum Zinc, Calcium and Magnesium in test group are $0.47 \mathrm{mg} / \mathrm{L}, 8 \mathrm{mg} / \mathrm{dL}, 1.4 \mathrm{mg} / \mathrm{dL}$ respectively, and the mean of the serum Zinc, Calcium and Magnesium in cataract patients $0.2 \mathrm{mg} / \mathrm{L}, 7.8 \mathrm{mg} / \mathrm{dL}, 1.3 \mathrm{mg} / \mathrm{dL}$ respectively (Figures 1 and 2).

Table 1 show significant low in serum Zinc between case and control group P-value $(<0.001)$, also significant low were observed in serum Magnesium level between test and control group P-value (0.017) but insignificant difference were observed in serum Calcium levels between test and control group P-value (0.16).

Table 2 show positive significant correlation between serum Magnesium level and Calcium level (R-value 0.615) P-value

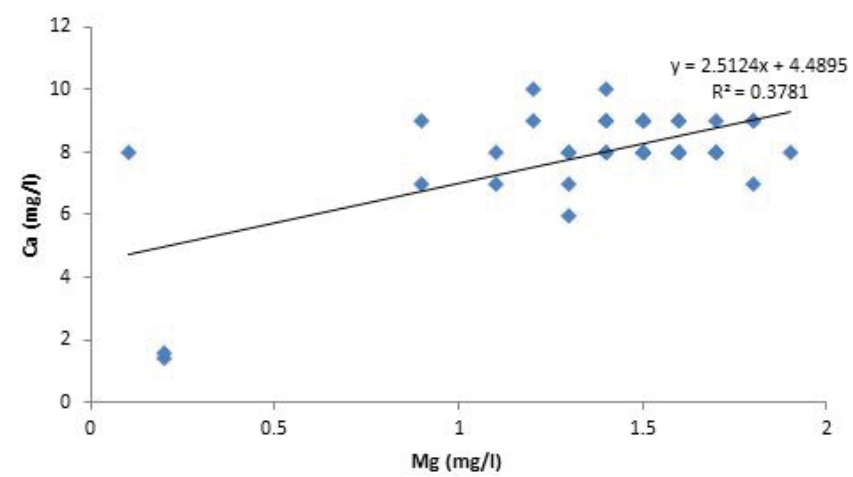

Figure 1: Correlation between serum Calcium and the Magnesium in case study group.

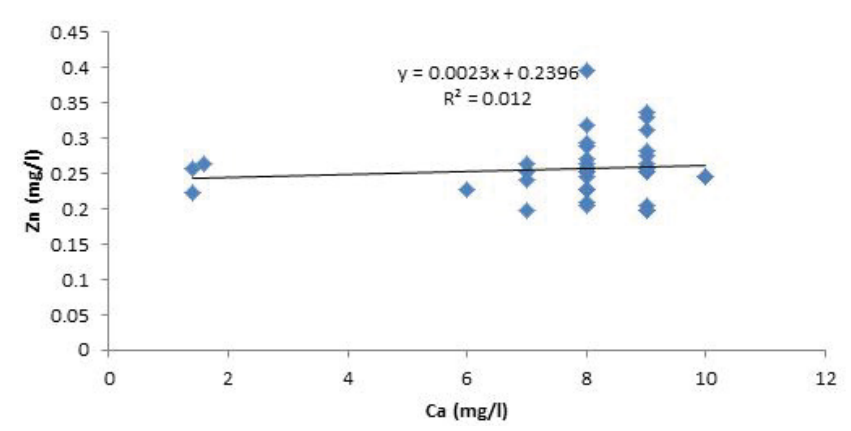

Figure 2: Correlation between serum zinc and the Calcium in case study group.

Table 1: The mean differences between case and control group.

\begin{tabular}{|c|c|c|c|}
\hline Parameters & $\begin{array}{c}\text { Control (Mean } \\
\pm \text { SD) }\end{array}$ & $\begin{array}{c}\text { Patients (Mean } \\
\pm \text { SD) }\end{array}$ & P-value \\
\hline Zinc & $0.47 \pm 0.14$ & $0.27 \pm 0.04$ & $<0.001$ \\
\hline Magnesium & $1.47 \pm 0.18$ & $1.31 \pm 0.41$ & 0.017 \\
\hline Calcium & $8.00 \pm 1.23$ & $7.82 \pm 1.98$ & 0.16 \\
\hline
\end{tabular}

Independent t-test was used to calculate P-value

$\mathrm{P}$-value considered significant when it less than 0.05

Table 2: Correlation between serum levels of zinc, magnesium with Calcium in case study group.

\begin{tabular}{|c|c|c|}
\hline & \multicolumn{2}{|c|}{ Calcium } \\
\hline & R-value & P-value \\
\hline Zinc & $0.615^{* *}$ & $<0.001$ \\
\hline Magnesium & $0.110^{\text {ns }}$ & 0.501 \\
\hline \multicolumn{3}{|c|}{$\begin{array}{l}\text { BivariatePearson`s correlation test was used } \\
\text { R-value }<1>\text { and } P \text {-value less than } 0.05 \text { considered significant }\end{array}$} \\
\hline
\end{tabular}

$(<0.001)$. Also positive insignificant correlation were observed between serum Calcium levels and Zinc levels R-value (0.110) P-value (0.501).

\section{Discussion}

Increased generation of the free radicals and decreased antioxidant Activity Superoxide dismutase has been proposed to play an important role in cataract formation in senile age group in various earlier and recent studies $[11,12]$. This study investigated the serum levels of Zinc, Calcium and Magnesium among patient with senile cataract. The study revealed there was significant difference low in serum zinc between test and control cataract. So low level of zinc may lead to failure SOD stability and lead to formation of cataract); this study agree with study group. Zinc is an important element for maintaining the stability of antioxidant Superoxide dismutase $[9,13]$ that eliminate the formation of was done by Indranil, et al. [14]. And disagree with study done by Cumurcu, et al. [15] On other hands The study revealed there was significant difference low in serum Magnesium level between test and control group Magnesium play an important role in maintaining lens homeostasis. Therefore, in Mg-deficiency states, ATPase dysfunctions which leads to the denaturation of crystalline, the soluble lens protein required for maintaining the transparency of the lens. Also $\mathrm{Mg}$ deficiency enhances lenticular oxidative stress by increased production of free radicals and depletion of antioxidant defenses [10]. And help in formation of cataract this study agree with study was done by Agarwa, et al. [10]. The study revealed there was in significant difference low in serum calcium levels 
between test and control. Calcium help as cofactor with ATPase enzyme to produce crystalline so insignificant result may be due to problem found in ATPase enzyme on other Calcium is very sensitive element their levels may affect by many factors. This study disagree with study was done by Cumurcu, et al. [15]. In previous study daily oral supplementation with $80 \mathrm{mg}$ of zinc as zinc oxide combined with $2 \mathrm{mg}$ of copper as cupric oxide for 5 years in the Age-Related Eye Disease Study (AREDS), resulted in a median increase in zinc levels of $17 \%$ after 5 years of supplementation [16]. Serum level of zinc calcium and Magnesium among patients with senile Cataract was significantly low in this study, oral zinc supplementation was found in a short-term pilot study reduce the risk of vision loss in persons with age-related macular degeneration [17].

\section{Conclusion}

The study conducted that the serum levels of Calcium, magnesium and Zinc were lower among patients with cataract this association findings conduct that serum zinc and magnesium levels have associated with increasing severity of senile cataract and cataract risk factors and supplemental zinc, Calcium and magnesium require intake on cataract.

\section{Ethical Consideration}

The study received ethical clearance from the ethical committee of Faculty of Medical Laboratory Science, ALzaeim Alazhari University, Sudan.

\section{Acknowledgement}

Authors would like to thank the patients from Khartoum state who were involved in the study and medical staffs of Makkah Eyes hospital.

\section{References}

1. Duncan G, Jacob TJ. Calcium and physiology of cataract. Ciba found symp. 1984;(106):132-52.

2. Milacic S. Risk of occupational radiation induced cataract in medical works. Med Lav. 1998;(3):178-86.

3. Consul B, Charan SS, Sharma R. A study of interrelationship between the lenticular and blood calcium contents in various types of human cataractous lenses. J All india ophthalmol. 1970;22(3):99-105.
4. Mezzetti A, Pierdomenico S, Costantini F, et al. Copper and zinc ratio and systemic oxidant load. Free Rad Bio I Med. 1998;(25):676-81.

5. Jacques P, Chylack L, McGandy RB, et al. Antioxidant status in person with and without senile cataract. Arch Ophthalmol. 1988;106(3):337-40.

6. Micelli-Ferrari T, Vendemiale G, Grattagliano I, et al. Role of lipid peroxidation in the pathogenesis of myopic and senile cataract. Br J Ophthalmol. 1996;80(9):840-3.

7. Klug-Roth D, Fridovich I, Rabani J. Pulse radiolytic investigation of superoxide catalyzed disproportionation.Mechanism for boving superoxide dismutase. J Am Chem Soc. 1973;95(9):2786-90.

8. Klug D, Rabani J, Fridovich I. A direct demonstration of the catalytic action of superoxide dismutase through the use of pulseradiolysis. J Biol Chem 1972;247(15):4839-42.

9. Forman HJ, Fridovich I. On the stability of bovinesuperoxide dismutase. The effect of metals. J Biol Chem 1973;248(8):P2645-9.

10. Agarwal R, Iezhitsa IN, Agarwal P, et.al. Mechanisms of cataractogenesis in the presence of magnesium deficiency. Magnes Res. 2013;26(1):2-8.

11. Fuziwara H, Takigawa Y, Suzuki T, et al. Superoxide dismutase activity in cataractous lenses. Jpn J Opthalmol. 1992;36(3):273-80.

12. Augasteyn R. Protein modification by cataract formation. Academic Press, New York 1981;71-115.

13. Fee J, Briggs R. Studies on the reconstitution of bovine erythrocyte superoxide dismutase. V. Preparation and properties of derivatives of in which both zinc and copper sites contain copper. Biochim biophys Acta. 1975;400(2):439-50.

14. Indranil C, Sanjoy K, Mousumi B, et al. Evaluation of serum Zinc level and plasma SOD in senile cataract patients. Indian J Clin Biochem. 2007;22(2):109-13.

15. Cumurcu T, Mendil D, Etikan I. Levels of zinc, with pseudoexfoliative cataract. Eur J Ophthalmol. 2006;16 (4):548-53.

16. Age-Related Eye Disease Study Research Group. The Effect of Five-Year Zinc Supplementation on Serum Zinc, Serum Cholesterol and Hematocrit in Persons Randomly Assigned to Treatment Group in the Age-Related Eye Disease Study: AREDS. J Nutr. 2002;132(4)4:697-702.

17. Newsome DA1, Swartz M, Leone NC. Oral zinc in macular degeneration. Arch Ophthalmol. 1988;106:192-8.

\section{*Correspondence to:}

Abdalla E Ali

Department of Clinical Chemistry

Faculty of Medical laboratory Sciences

Alzaiem Alazhari University

Sudan

Tel: 00249123075933

E-mail: abdalla.ali2087@yahoo.com 